\title{
Valid for Who? A Preliminary Investigation of the Validity of Two Sexual Victimization Questionnaires in Men and Sexual Minorities
}

\author{
RaeAnn E. Anderson \\ University of North Dakota, raeann.anderson@UND.edu \\ Emily M. Carstens Namie \\ University of North Dakota, emily.carstensnamie@und.edu \\ Erica Goodman
}

\section{How does access to this work benefit you? Let us know!}

Follow this and additional works at: https://commons.und.edu/psych-fac

Part of the Psychology Commons

\section{Recommended Citation}

RaeAnn E. Anderson, Emily M. Carstens Namie, and Erica Goodman. "Valid for Who? A Preliminary Investigation of the Validity of Two Sexual Victimization Questionnaires in Men and Sexual Minorities" (2021). Psychology Faculty Publications. 36.

https://commons.und.edu/psych-fac/36

This Article is brought to you for free and open access by the Department of Psychology at UND Scholarly Commons. It has been accepted for inclusion in Psychology Faculty Publications by an authorized administrator of UND Scholarly Commons. For more information, please contact und.commons@library.und.edu. 
-

\section{Valid for who? A preliminary} investigation of the validity of two sexual victimization questionnaires in men and sexual minorities
American Journal of Criminal Justice (C) The Author(s) 2020 Not the version of record. The version of record is available at DOI: $10.1007 /$ s 12 103-02009589-3

\title{
RaeAnn E. Anderson ${ }^{1,2}{ }^{\oplus}$, Emily M. Carstens Namie ${ }^{1}$, and Erica L. Goodman ${ }^{1,3}$
}

\begin{abstract}
The \#MeToo movement illuminated vast numbers of people who experienced sexual violence, but the exact scope and impact, especially among under-studied populations (e.g., men and sexual minorities) is unclear, due in part to measurement issues. Our objective was to compare the validity of two measures of sexual violence victimization: The Sexual Experiences Survey - Short Form Victimization (SES-SFV) and The Post-Refusal Sexual Persistence Scale - Victimization (PRSPS-V). Participants were 673 college students who first completed the Rape Empathy for Victims (REM-V) and then the SESSFV and PRSPS-V (counter-balanced). We found strong evidence of convergent validity for the PRSPS- $V$ with correlations ranging from $r=.57-88$. Convergent validity correlations were strongest for sexual minority women $(r=.88)$ and weakest for heterosexual men $(r=.57)$. We also found evidence of differential validity for the SES-SFV and PRSPS-V. For heterosexual women, rape empathy was correlated to victimization on both questionnaires $(r=.25-.29)$. However, for heterosexual men, only scores on the SES-SFV were correlated with rape empathy for victims $(r=.19)$. For sexual minorities there appeared to be differences between PRSPS-V only victims and those who reported victimization on both questionnaires in rape empathy $(F=2.65, p=.053)$. These results provide researchers a starting point for improving these questionnaires to collect more accurate data that helps improve the ability to detect cases of sexual victimization and thus, prevent and heal sexual victimization, especially in understudied populations such as men and sexual minorities.
\end{abstract}

\section{Keywords}

Rape, sexual minority, health disparities, assessment, measurement, sexual assault

I Department of Psychology, University of North Dakota, Grand Forks, ND, USA

2 Department of Psychological Sciences, Kent State University, Kent, OH, USA

3 Department of Psychiatry \& Behavioral Sciences, Northwestern University, Evanston, IL, USA 
Rape affects approximately one in five college women (Koss et al., 1987; Muehlenhard et al., 20I7), one in seven college men (Anderson et al., 2018a), and even more sexual minority students (i.e., people who identify as gay, lesbian, bisexual, queer, or another minoritized sexuality). Sexual minority college women are 1.5-4X more likely to experience sexual violence, and sexual minority men are approximately $3 \mathrm{X}$ more likely to experience rape compared to their same gender heterosexual peers (Anderson et al., 2017; Martin-Storey et al., 2018). The plight of these and other individuals who have experienced sexual violence in their lifetime was brought to the forefront of the world stage beginning in October 2017 with the extraordinary growth of the \#MeToo movement. Within the first 24 hours of the post calling for individuals who have experienced sexual harassment or violence to use \#MeToo, the hashtag was tweeted a million times on Twitter and gathered 12 million posts and comments on Facebook worldwide. Within a few days, $45 \%$ of Facebook's 220 million users (approximately 99 million people; Clement, 2019) in the United States had at least one friend who posted \#MeToo (CBS News, 20 I7). A study investigating the prevalence of sexual violence illuminated by the \#MeToo movement found that $27 \%$ of women and $7 \%$ of men experienced sexual assault; and $51 \%$ of women and $17 \%$ of men reported unwanted sexual touching (Kearl, 2018). Yet, the symbolic stories of \#MeToo have been primarily of men as perpetrators and women as victims (e.g., Harvey Weinstein, Bill Cosby). Recent research has begun to move the needle to include a broader perspective of who is harmed by sexual violence. Data from \#MeToo shows that sexual violence is more prevalent for sexual minorities; $48 \%$ of sexual minority women and $19 \%$ of sexual minority men experienced sexual assault, compared to $25 \%$ of heterosexual women and $6 \%$ of heterosexual men (Kearl, 2018). Yet, an understanding of the best measurement and methodology to sensitively and scientifically capture the experiences of men and sexual minority individuals is sorely lacking.

For example, estimates of sexual violence victimization in men range from $2 \%$ to $73 \%$, illustrating definitional and measurement issues (Peterson et al., 2010) in addition to the stigma of sexual victimization which can suppress reporting (Wolitzky-Taylor et al., 201 I). Further, although people who identify as sexual minorities experience sexual victimization at much greater rates than people who identify as heterosexual, they have been largely excluded from research on the measurement of sexual victimization. This raises questions about the validity of sexual victimization questionnaires when used with sexual minority populations (Anderson et al., 2019). Before researchers can identify risk factors and test state-ofthe-art interventions to help prevent and heal sexual victimization, valid and reliable measures of sexual violence that are inclusive of all individuals' experiences are needed. Therefore, the goal of this study is to compare the validity of two different measures designed to assess sexual violence victimization histories, The Sexual Experiences Survey - Short Form Victimization (SES-SFV) and The Post-Refusal Sexual Persistence Scale - Victimization (PRSPS-V), in a sample of college men and women that is also inclusive of sexual minorities.

\section{Validity of the SES-SFV}

Research has demonstrated good evidence of validity of the SES-SFV; though this conclusion is often cited without specifiers for which populations and under which conditions. SES-SFV scores are correlated with measures of psychiatric symptoms in both college and young community women (Davis et al., 2014; Johnson et al., 2017) and with reports of intimate partner violence victimization (Davis et al., 20l4). Yet, a closer examination of the literature reveals important details. When assessing these same constructs with college men as with women, validity correlations are lower (Anderson et al., 2018a). Specifically, the SES-SFV is correlated with intimate partner violence victimization at $r=.31$ in a sample of community women (Davis et al., 20l4); in college men this correlation is $r=.20$ (Anderson et al., 2018a). In comparing correlations across measures of sexual victimization, Johnson et al. (2017) reported that the SES-SFV is correlated with the 1987 SES at $r=.52$ with college women (men were not sampled), French et al. (2017) found correlations of $r=.36-.40$ (depending on the type of tactic) between the 1982 SES and the Sexual Coercion Inventory in a sample of male youth (women were not sampled). This suggests that the SESSFV may have poorer evidence of validity in college men than women but thus far, little to no research has included both men and women to compare these correlations and more conclusively assess the matter. Models of scale development suggest including all target populations during the development phase to increase validity (American Educational Research Association, 2014). Therefore, it is to some extent expected that the SES-SFV would have different and perhaps even poorer psychometric properties with men, given that the SES and its subsequent revisions were developed with women, excluding men. Indeed, as noted by Buday and Peterson (2015), given that most sexual victimization questionnaires were developed with samples of primarily heterosexual women, it is possible that no available questionnaires adequately capture men's experiences. 
And yet, there is even less data available to evaluate the validity of sexual victimization questionnaires for sexual minorities. To our knowledge there are only three measurement focused studies that included sexual minorities but Johnson et al. (2017) and Anderson et al. (2018a) did not analyze their data separately. Canan and colleagues found that bisexual and lesbian women endorsed SES-SFV items at similar rates to heterosexual women; however, in open-ended narratives sexual minority women described some experiences not captured by the SES-SFV suggesting room for improvement.

\section{Validity of the PRSPS-V}

Compared to the SES and its iterations, the psychometric properties of the PRSPS- $V$ are less established, much less with specific subpopulations. However, the PRSPS-V is unique in that this questionnaire was developed specifically to capture potential gender differences in sexual victimization experiences. The PRSPS-V assesses a wider range of tactics, including tactics drawn specifically from the literature on men's experiences of sexual victimization (Struckman-Johnson et al., 2003). For example, the use of enticement or seduction to coerce sex is included on the PRSPS-V and may be especially used against men (French et al., 20I5). Because of the sexual behavior focused (and thus, genital focused) nature of the SES-SFV items, some have suggested that the SES-SFV items are inherently gendered (Anderson et al., 2018b; Anderson \& Delahanty, 2019). In contrast, the PRSPS-V uses a structure that may minimize reported gender differences by focusing less on specific sexual behaviors and acts (Anderson \& Delahanty, 2019). With a sample of college men and women, Struckman-Johnson et al. (2003) found good evidence of construct validity, but few details were provided on the validity data. Subsequent studies examining convergent validity have only recruited women (Katz \& Tirone, 2008; Turchik \& Hassija, 20I4); ignoring the sexual victimization experiences of men and sexual minorities. Finally, no study has compared PRSPS-V and SES-SFV scores. Given the comparative wealth of research on the SESs, this is an important comparison point to assess the convergent validity of the PRSPS-V.

\section{Differential Validity}

In addition to evaluating the convergent validity of the PRSPS-V by correlating its scores with SES-SFV scores, comparing each questionnaires' scores to a third construct could highlight differential validity. For example, if the SES-SFV was more strongly correlated to a third, related construct in the nomological network of sexual victimization than the PRSPS- $V$, this would demonstrate greater evidence of convergent validity for the SES-SFV. To date, research examining the validity of these measures has largely focused on clinical constructs. This is appropriate given the serious mental and physical health consequences of rape, such as increased pain, risk for psychiatric disorders, and depressed economic productivity (Koss, 1993). Yet, the nomological network of rape victimization (i.e., the network of theorized constructs and expected relationships: Anderson et al., 2018a, Cronbach \& Meehl, 1955) encompasses a variety of constructs, including clinical, legal, and attitudinal constructs.

Rape empathy is an attitudinal construct with clinical and legal implications. Rape empathy represents the ability to understand the emotions and reactions of someone who has experienced rape victimization (Smith \& Frieze, 2003). Theory suggests this type of perspective taking is important in a variety of ways, including providing therapeutic services and in jury decision-making (Smith \& Frieze, 2003). For instance, initial research on mock jurors using the Rape Empathy Scale (Deitz et al., 1982) found that mock juror sentencing decisions are impacted by individual differences in rape empathy. More specifically, mock jurors with higher rape empathy for the victim were more likely to find the defendant guilty, be more certain about the defendant's guilt, attributed more responsibility to the defendant, and assigned longer prison terms (Deitz et al., 1982; Weir \& Wrightsman, 1990). Furthermore, female mock jurors who had personally experienced rape were significantly higher in rape empathy than those who had not been sexually assaulted (Deitz et al., 1982). Male jurors who were higher in rape empathy reported less desire to rape women than their lower empathy counter-parts (Deitz et al., 1982). Clinically and socially, empathy for rape victims is related to prosocial helping behavior when receiving rape disclosures (Edwards et al., 2020), an important finding for improving community attitudes and behaviors regarding rape. These findings suggest the rape empathy construct has potential for the development of rape prevention and community engagement strategies. However, past juror rape empathy research was largely conducted with older questionnaires that conflated empathy towards victims with antipathy towards perpetrators when in fact, empathy towards victims and empathy towards perpetrators are parallel constructs which can and do exist simultaneously (Smith \& Frieze, 2003). 
More recent research conceptualizing rape empathy in parallel structures above suggests that rape empathy reflects the gender and sexual identity based stereotypes embedded in our culture. Women are more empathic towards victims than men (even men with victimization histories) and non-victims and men are the least empathic towards other men who have been victimized (Osman, 20I I, 20I4). A reliable finding from the rape empathy and related literature is that women who have experienced victimization tend to have the greatest levels of rape empathy for (hypothetical) victims (Osman, 20II, 20I4). The experience of victimization likely sensitizes individuals to the reality of rape and challenges rape myths. Given the replicated findings of rape empathy across genders and victimization histories this construct is helpful for demonstrating validity in that we can expect to find specific patterns. Similar to the larger literature on sexual violence, research on rape empathy has largely excluded sexual minorities.

\section{Current Study}

Building the awareness and knowledge of the broader impacts of sexual violence beyond the stereotypical heterosexual woman victim and heterosexual male perpetrator, we chose to extend the literature by focusing on the validity of two measures of sexual victimization in a population of college students that included men, women, and sexual minorities. We chose to compare the PRSPS-V and the SES-SFV across genders and sexual identities because the SES-SFV is well-used and -researched and the PRSPS-V was developed to detect gender differences. Thus, the PRSPS-V may be especially useful for work with men and sexual minorities should it exhibit similar properties to the SES-SFV.

Hypotheses:

I. Convergent validity of the PRSPS-V: We hypothesized that the PRSPS-V and the SES-SFV would be moderately-strongly correlated ( $r \approx .5$ : $\mathrm{Hla}$ consistent with Johnson et al., 2017, French et al., 2017) but that these correlations would be of lesser strength for men than women (HIb: Anderson et al., 20I8a; French et al., 2017). We made no hypotheses about the strength of these correlations for sexual minorities given the lack of available literature.

2. Differential validity: We expected that both the SES-SFV and PRSPS-V would be correlated with a measure of rape empathy for victims at approximately $r=.3(\mathrm{H} 2 \mathrm{a}$ : Osman, 2016) and that this relationship would be stronger for women than men and weaker for those without victimization histories (Deitz et al., 1982). To further assess differential validity we will analyze how rape empathy varies by SESSFV/PRSPS-V response patterns. We made no hypotheses about differential validity between the three constructs except that rape empathy would be highest among those with victimization histories $(\mathrm{H} 2 \mathrm{~b}$ : Osman, 2016), given lack of prior research.

\section{Method}

\section{Participants}

Participants were 673 college students with a mean age of I9.5 (SD = 3.6). Participants were asked to identify their sex/gender from the following list: female, male, transgender, Other (please describe). Women comprised $54.5 \%$ of the sample, men - $44.3 \%$, and transgender and other gender identities I.I\%. Participants were asked to select their sexual identity from a list of options: bisexual, heterosexual, gay, queer, other (please describe). Most participants reported being heterosexual (85.6\%); some were bisexual (5.6\%), gay (4.9\%), and queer (I.5\%). A small number of participants reported their sexual orientation as other $(n=3 \mathrm{I})$. On reviewing the descriptive labels provided by participants, sixteen of these participants were re-classified as heterosexual because they provided self-labels consistent with heterosexuality (e.g., "regular" or "straight"). The remaining I 5 participants who selected "other" used a label that could be classified as sexual minority for example, "biromantic" and "pansexual." Bisexual participants were mostly women ( $n=44,24$ women) gay or lesbian participants were mostly men $(n=34,10$ women), the remaining participants identified as queer and mostly non-male $(n=10,5$ gender minorities, 4 women). Participants were mostly White (85.6\%); some were African American (9.4\%), Asian American (3.7\%), and Native American (I.0\%). A few participants reported identifying as Latinx (3.7\%). The average income of participants' families was in the $\$ 60,000-79,999$ range. 


\section{Measures \\ Questionnaires Assessing Sexual Violence Victimization.}

The Sexual Experiences Survey - Short Form Victimization (SES-SFV: Koss et al., 2007). The SES-SFV consists of compound, behaviorally-specific items that each begin with a description of a sexual behavior (i.e., "Even though it didn't happen, a man TRIED to put his penis into my vagina, or someone tried to stick in fingers or objects without my consent by:...") followed by five possible tactics that were used to coerce the respondent (five categories are: verbal criticism, verbal pressure, alcohol incapacitation, threats of physical force, physical force). This creates 25-35 items depending on the respondent's gender (people with vaginas complete more items) by crossing each sexual behavior phrase with each tactic description. For this study, we utilized a dichotomous response format (yes or no) to assess whether each experience had ever occurred since age 14. The SES-SFV has demonstrated good test-retest reliability in past research with college women (Johnson et al., 2017) and adequate test-retest reliability in college men when scored dichotomously (Anderson et al., 2018a).

The Post-Refusal Sexual Persistence Scale (PRSPS-V: Struckman-Johnson et al., 2003). The PRSPS-V contains 19 items that assess sexual victimization in relation to five different types of tactics: enticement, verbal coercion, misuse of authority, alcohol/drugs, and physical force. Rather than each item containing information about a sexual behavior and a tactic used to obtain it, the PRSPS- $V$ defines sexual contact in introductory instructions as "genital touching, oral sex, or intercourse" and then gives a list of 19 tactics as items such as "gave you alcohol or drugs to get you high." We were unable to locate any estimates of test-retest reliability for the PRSPS-V. Given the goal of our study is to compare the validity of the PRSPS$V$ and the SES-SFV, and prior work suggesting differences between these measures contribute to discrepancies, we made some small modifications to the PRSPS-V to make it more comparable to the SES-SFV. We revised the introductory text to make the definition of sexual contact more broad and consistent with the SES-SFV, then we made the perpetrator of the items gender-neutral (e.g., they vs. he) and used "since age 14" as the time frame for the assessment period. These changes have been made in prior research to clarify the instrument and increase its utility and do not appear to adversely impact validity (Strang et al., 2013).

Scoring. We computed two types of scores for this study, dichotomous and continuous. For dichotomous scores, participants who responded "yes" to any item on either questionnaire were coded as having a history of sexual victimization. We computed continuous scores for correlational analyses; endorsement of any item on the SES-SFV or PRSPS-V was coded as a "I" and then summed. Finally, we did not compute Cronbach's alpha for either questionnaire as Cronbach's alpha is a measure of reliability recommended for latent constructs. Koss et al., (2007) suggested that it is inappropriate to consider the SESSFV and related questionnaires as measures of latent constructs because there is no hypothesized trait within participants that is presumed to cause sexual victimization. Nor are different experiences of sexual victimization necessarily related.

\section{Questionnaire Used to Assess Validity.}

Rape Empathy for Victims (REM-V: Smith \& Frieze, 2003). The REM-V consists of 18 items such as "I can understand how helpless a rape victim might feel" rated on a 5-point Likert scale from 5 = "strongly agree" to I = "strongly disagree." Due to a clerical error, in this study the response poles were switched such that "strongly disagree" was coded 5 . We conducted a factor analysis to assess whether this clerical error affected the structure of the instrument. Smith and Frieze, (2003) reported a two factor, varimax rotated structure account for $67 \%$ of the variance, with the two factors representing empathy related to experiences during the assault versus post-assault. Our findings were similar. We found three varimax rotated factors accounting for approximately $66 \%$ of the variance. Two of the extracted factors followed the pattern reported in Smith and Frieze (2003) with items corresponding to during vs. post-assault empathy. The proposed third factor in our data consisted of three items seeming to represent ambivalence about rape victims; these items were also reverse scored. Two of these items also loaded highly on the 2nd factor, post-assault empathy. Given these similarities and issues with reverse-scored items generally (Woods, 2006) we continued with the proposed rape empathy analyses.

Because of the clerical error, higher scores would have indicated less empathy. To preserve comparisons with prior literature and ease interpretation we reverse scored items I-I3 and I7-18 instead of items 14-16. This allowed us to interpret higher scores as indicative of greater empathy. The REM-V improves on prior measures of rape empathy by specifying empathy felt towards the victim/survivor 
separately from that felt towards the perpetrator. REM-V scores are positively related to a history of sexual victimization (Osman, 20II). In this study, Cronbach's alpha $=.91$.

Procedures

Data were collected anonymously through Qualtrics between September and December 2017. The study was approved by the Institutional Review Board at Kent State University and was advertised as "Questionnaires about Sexual Behavior" in the Sona experiment management system. Participants completed the REM-V and then the victimization history questionnaires, SES-SFV and PRSPS-V, which were counterbalanced. Another paper from this same dataset has been published (Anderson \& Delahanty, 2019) examining sexual violence measurement discrepancies and one additional measure was also administered to evaluate understanding of consent, a separate manuscript investigating these findings is in preparation.

\section{Results}

Data cleaning and power analysis

Any participant who completed at least one item on the SES-SFV and the PRSPS-V was included; 673 participants met these criteria. Missing data for SES-SFV and PRSPS-V items was minimal, $5 \%$ or less per item; missing items were assumed to be the modal value, zero. While simple, this approach to analyzing missing data has been found comparable to more complex approaches, such as multiple imputation, for larger samples with low levels of missing data such as this one (Parent, 20I3). Participants who completed between $75-99 \%$ of the REM- $V$ had their scores prorated; only 4 participants completed too little data to be included.

Skewness and kurtosis were within limits for most variables (Tabachnick \& Fidell, 2007). Skewness and kurtosis was outside of $+/-2$ for SES-SFV continuous scores, kurtosis was 16.16. Following, Spearman's rank (rho) correlations are reported for the below correlational analyses. According to a priori power analyses, we had a sufficient sample size to detect most small effects $(r=.10$, suggested $n=614$ for Power $=.80)$ for correlational analyses.

\section{Descriptive Results}

The prevalence rates of any sexual victimization on either questionnaires were: heterosexual women $-64.6 \%$, sexual minority women $-62.2 \%$, heterosexual men $-36.8 \%$, sexual minority men $-46.7 \%$. Most of the gender minority participants also identified as sexual minorities (87.5\%); all eight of the gender minority participants reported experiencing sexual victimization. Table I presents descriptive information on the type of victimization captured by each questionnaire across the sample groups. For example, rape was most frequently reported by gender minorities (50.0\%) and women (30-31\%) and least by heterosexual men $(8.7 \%)$.

The prevalence rates were not significantly different between the two groups of women (sexual majority vs. minority, $\chi^{2}(I)=.10, p=.755$ ) or the two groups of men (sexual majority vs. minority, $\chi^{2}(I)=$ $1.33, p=.248)$. The prevalence rates were significantly different between heterosexual men and women $\left(\chi^{2}(I)=4 I .52, p<.00 I\right)$, but not sexual minority men and women $\left(\chi^{2}(I)=2.17, p=. \mid 4 I\right)$.

\section{Hypothesis I: Validity of the PRSPS-V and SES-SFV across groups}

The SES-SFV and PRSPS-V were strongly correlated in the entire sample. The relationship between the measures was strongest when measured continuously, and this difference, in comparison to dichotomous scores, was statistically significant, $z=4.23, p<.000 \mathrm{I}$. Correlations between the SES-SFV and PRSPS-V were stronger for women, $r(367)=.65, .80, p<.001$ than for men, $r(298)=.53, .62, p<.00 \mathrm{I}$. Correlations were strongest for sexual minority women, $r(45)=.78, .88$ and weakest for heterosexual men, $r(253)=.49, .57$, see Table 2 for further statistical comparisons.

\section{Hypothesis 2: Differential validity}

Rape empathy was significantly correlated with both the SES-SFV and the PRSPS-V in the entire sample, $r=.30$ and .27 , respectively. However, the strength of these relationships did vary by sexual identity 
and gender group. To wit, for heterosexual women, these relationships were of similar strength, $r=.25$ and .29. However, for men only the SES-SFV and REM-V were significantly correlated and the strength of this relationships was weaker, $r=.19$. For men, there was no significant relationship between sexual victimization as measured by the PRSPS- $V$ and rape empathy for victims. For sexual minorities, none of these relationships were significant; however, these analyses were under-powered given the weaker than expected relationship between victimization scores and rape empathy, see Table 3 .

We also computed one-way ANOVAs to assess whether REM- $V$ scores varied among the four possible patterns of disagreement on the SES-SFV and the PRSPS-V (both questionnaires agree no (I), SESSFV yes/PRSPS-V-V no (2), SES-SFV no/PRSPS-V yes (3), both questionnaires agree yes (4)). This analysis was suggested by prior researchers as a method to identify differential validity (Anderson et al., 20l8b). We ran analyses separately by gender and sexual identity; we considered sexual identity dichotomously considering low statistical power but did examine the means by gender and sexual identity to clarify observed effects. The omnibus effects were significant for heterosexual women $(F(3,3 \mid 5)=8.14, p<$ $.000 \mathrm{I})$, heterosexual men $(F(3,249)=3.28, p=.022)$ and marginal for sexual minorities as a group $(F(3$, $93)=2.650, p=.053$ ). Follow-up Tukey's tests for women and men indicated significant differences between groups I (double non-victims: SES-SFV no/PRSPS-V no) and 4 (double victims: SES-SFV yes/PRSPS- $V$ yes), see Table 4 for means. However, upon inspecting means for sexual minority individuals, the largest numerical differences were between groups 3 (PRSPS- $V$ victims only) and 4 (double victims). This suggests that across gender and sexual identity groups, rape empathy was high in participants who were classified as victims on both questionnaires. However, there may be differences in the gender $X$ sexual identity groups as to who reported the lowest rape empathy for victims, see Figure I. For heterosexual men and women the patterns of empathy was similar. For sexual minorities, it appears that the pattern is different. However, given the small cell counts we consider this suggestive for future research.

\section{Discussion}

The \#MeToo movement helped to give a voice to approximately 99 million Americans who have experienced sexual violence, illuminating the vast prevelance of this often hidden violation. Researchers find that sexual violence effects as many as one in four college women, one in six college men, and even more sexual minority college students (Anderson et al., 2017; Martin-Storey et al., 2018) but sexual minority individuals and male victims have been largely excluded from sexual violence measurement science. This study compared two well-used measures of sexual violence victimization to document evidence of validity in men and sexual minorities and to assess the differential validity of these measures for college students. In this study, we found good evidence of validity for the PRSPS-V but that validity correlations and patterns varied by gender and sexual identity.

\section{Convergent Validity}

We found strong evidence of convergent validity for the PRSPS- $V$ in college students including men, women, and sexual minorities. Indeed, correlations were stronger than expected $(r=.50-.88$, H Ia), suggesting the PRSPS- $V$ is a promising measure of sexual victimization, especially considering that correlations were very strong for sexual minorities. This is particularly notable in that measures with less published validity evidence (such as the PRSPS-V) often "fall apart" in terms of psychometric properties when put under further scrutiny after initial publication (Hussey \& Hughes, 2020). Weaker validity correlations for men are consistent with prior research and hypotheses (H lb: Anderson et al., 20 I8a; French et al., 2017); however, this research clarifies that the gender difference identified in prior research may really be a gender $X$ sexual identity difference. Only validity correlations for heterosexual men were significantly weaker than women's. Interestingly, it is unclear what the source of this difference in validity is. As Buday and Peterson (2015) suggested, it may be that men's experiences have been so inadequately represented in the literature our available measures do not capture them, even using a questionnaire such as the PRSPS- $V$ that is designed to assess gender differences. But, given this finding was specific to heterosexual men, the lower validity correlations may also reflect a weakness in the research in capturing women's perpetration behavior (Stemple \& Meyer, 2014). For example, heterosexual men are much more likely to experience made to penetrate victimization than women, a type of sexual perpetration primarily instigated by heterosexual women (Anderson, Goodman, \& Thimm, 2020). This possibility, that currently available measures neglect heterosexual men's victimization experiences and heterosexual women's perpetration is also consistent with our findings that validity correlations were significantly stronger for sexual minority men. Sexual minority men are more likely to be harmed by other men 
(Anderson et al., 2017). It could be that sexual minority men find more relatable content in questionnaires that conceptualize men as perpetrators, such as the SES-SFV.

Alternatively, it may also be that the stereotype of men as perpetrators is so strong that heterosexual men, who are more likely to endorse traditional masculinity (Wade \& Donis, 2007), need some type of additional cue or instruction to be able to accurately recall victimization experiences, since these experiences are so counter to stereotype. Other research has demonstrated the importance of specific, simple cues for overcoming rape specific stereotypes (rape myths) in self-report (Fisher, 2009). For example, a simple instruction to consider intimate partners as perpetrators increases reports of sexual violence perpetrated by intimate partners; counter to the myth that a spouse cannot be raped by their spouse (Anderson et al., 2020).

Finally, we find it curious that the PRSPS-V and the SES-SFV are more strongly correlated $(r=.57-.88$ in this study) than the SES-SFV and the 1987 SES as reported by Johnson et al., 2017, $r=.52$ '. This suggests that the PRSPS-V and the SES-SFV are more strongly related than the SES-SFV and the 1987 SES, at least for women. This is consistent with Anderson et al.,'s (2019) suggestion that the SES-SFV is functionally a different questionnaire than the 1982 or 1987 SES. Perhaps this stronger relationship with the PRSPS-V reflects the efforts to decrease heterosexism in the SES-SFV.

\section{Differential Validity}

When considering differential validity our findings were consistent with simple predictions; rape empathy for victims was correlated with having experienced victimization on both questionnaires and men were less empathic than women $(\mathrm{H} 2)$. However, this relationship did not hold up to further scrutiny when examined by gender and sexual identity group - only the SES-SFV was correlated with rape empathy for male participants, the PRSPS- $V$ was not. We speculate this may be related to the differences in the types of victimization captured by the two questionnaires. For example, enticement victimization, also called seduction coercion in other work (French et al., 20I5), was reported by $25 \%$ of men and is not captured by the SES-SFV. For men, it may be that the relationship between rape empathy and victimization is influenced by severity - and the PRSPS-V appears to capture less severe cases that are missed by the SES-SFV. This does not impugn the validity of the PRSPS-V - at least not without further construct validity work to learn more about enticement victimization. Rather, this suggests that severity of victimization may be a driving factor in the relationship between rape empathy and victimization for men; further, we suspect this is primarily for heterosexual me.

Across men, women, and sexual minorities, participants with doubly confirmed histories of victimization (SES-SFV yes/PRSPS-V yes) reported the greatest rape empathy for other victims, consistent with hypotheses $(\mathrm{H} 2 \mathrm{a})$. But visually, there was not consistency in which group exhibited the lowest rape empathy for victims. The means were most consistent across groups for the PRSPS-V, in other words, those who endorsed victimization on the PRSPS- $V$ reported more similar levels of rape empathy regardless of gender or sexual identity than those who endorsed victimization on the SES-SFV. It may be that our initial correlational findings and evidence from prior research (Dietz et al., 1982; Osman, 2016) were likely driven by the sampling of mostly young heterosexual women and use of the SES-SFV. We add the caution that with our relatively small groups of sexual minorities and the relatively weak relationship between rape empathy and victimization, these findings should be considered suggestive and fodder for confirmation in future research. Factor analysis research to examine the structure of these questionnaires and to help determine if these questionnaires assess these same, unidimensional construct or not may be particularly useful. In this same vein, we recommend future research examine these relationships at the tactic/subscale level to elucidate the relationship between victimization severity and rape empathy.

In sum, we found strong evidence of convergent validity for the PRSPS-V and evidence of differential validity for the PRSPS-V and the SES-SFV. This suggests the possibility that the SES-SFV and PRSPS-V are actually assessing two different, yet related constructs. Although there are several differences between the questionnaires (we refer curious readers to Anderson \& Delahanty, 2019 for a detailed comparison), we suggest one source of construct differences is in how the two measures conceptualize consent. The PRSPS- $V$ conceptualization requires an initial advance that is refused ("after I indicated no") while the SES-SFV conceptualization ("without my consent") does not. This behavioral vs. internal-cognitive conceptualization may be interpreted differentially by participants; one study found that "without my consent" was considered a stricter standard by men (Strang \& Peterson, 2017). In addition, practically

${ }^{1}$ Johnson et al., $r(297)=.52$ between the SES 1987 and the SES-SFV for women; this paper $r(45)=.88$ for sexual minority women; $z=4.85, p<.00001$, compared to heterosexual women $r(322)=.78, z=5.80, p<.0000001$ 
speaking "after I indicated no" requires an explicit refusal of a behavior which would not apply to certain situations, such as a surprise attack by a stranger. Another relevant difference may be in the type of victimization/tactics measured.

\section{Limitations}

We consider further research on the psychometric properties of these questionnaires with sexual minorities highly important. Although this is the first study of its kind, our sample of people who identify as sexual minorities was rather small resulting in limited power for some analyses. Further, we were unable to embrace the heterogeneity of the LGBTQ+ population, not examining specific subgroups such as bisexual cisgender women. Nor did we elicit the full range of possible identities by providing options such as pansexual, asexual, among many others. We used an outdated and imprecise method for evaluating gender identity, conflating sex and gender. We recommend reseachers use a step-two approach or one of the methods recommended by Puckett et al. (2020). Finally, the sample overall was lacking in racial diversity. As our findings illustrate when it comes to sexual violence, what is true for heterosexual women is not true for all.

\section{Implications for Research}

We recommend further research on the psychometrics of sexual violence questionnaires. Including this paper, the number of papers on the psychometric properties of the SES-SFV and the PRSPS-V pales in comparison to the wealth of research conducted on the 1982 and 1987 SES. Specifically, more data are needed that are inclusive of men, sexual minorities, gender minorities, racial minorities, and that examine construct validity and test-retest reliability. For example, Littleton et al., (2019) found that a significant number of false-positive cases were identified by the SES-SFV (see also Strang \& Peterson, 2017). Yet, these measures are widely used, likely because the passion and drive of researchers to solve the problem of sexual violence overrides the lack of data. As noted by Flake and Fried (2019), there often appears to be an attitude of "measurement schmeasurement" in the literature with little attention paid to the threats of validity represented by questionable measurement practices. Modifying existing measures without disclosing the changes or documenting the psychometric properties of these modified questionnaires hinders overall scientific progress.

\section{Implications for Applied Work}

Ideally, legal and clinical work happen on the foundation of basic science. This ideal is rarely realized, but if we can learn anything from the \#MeToo movement it is the vast prevelance of unreported and underreported sexual violence. Policies that support basic science in legal and health disparities research are necessary to further investigate the questions raised in this paper and implement findings. Without adequate measurement, the validity of our data is questionable and we may be mis-estimating prevalence rates, effect sizes, and the efficacy of interventions which in turn can undermine attempts to combat sexual violence and its harmful effects. In applied settings, our findings suggest that careful attention be paid to the assessment of victimization experiences for men and for sexual minorities. Using multi-measure assessments may be a way to account for the potential issues of differential validity identified in this paper.

\section{Conclusions}

This study found strong evidence of validity for the SES-SFV and PRSPS-V when used to assess sexual victimization in women, men, and sexual minority college students. These types of gender and sexual identity differences have rarely been investigated in prior research which typically follows the femalevictim/male-perpetrator dyad. But, as demonstrated by the vast response to the \#MeToo movement, sexual violence affects more than just heterosexual women. To our knowledge, this is the first time the quantitative validity of the SES-SFV or the PRSPS-V has been investigated with sexual minorities (see also: Canan et al., 2019). In addition this study found evidence of differential validity for the SES-SFV and PRSPS$V$. These results give researchers a starting point from which to improve these questionnaires to collect more accurate, and thus useful data on sexual violence, especially in understudied populations such as men and sexual minorities. 


\section{Declaration of Conflicting Interests}

The author(s) declared no potential conflicts of interest with respect to the research, authorship, and/or publication of this article.

\section{Funding}

Dr. Anderson's work was supported by a grant from the National Institute on Alcohol Abuse and Alcoholism (5K0IAA026643-02). The content is solely the responsibility of the authors and does not necessarily represent the official views of the funding agency.

\section{ORCID iD}

RaeAnn E. Anderson (i) https://orcid.org/0000-000I-9938-0717

Emily Carstens Namie (iD https://orcid.org/0000-0003-0472-1369

Erica L. Goodman (iD https://orcid.org/0000-000 I-5819-8855 


\section{References}

American Educational Research Association, American Psychological Association, National Council on Measurement in Education (2014). Standards for educational and psychological testing. American Educational Research Association.

Anderson, R. E., \& Delahanty, D. L. (2019). Discrepant responding across measures of college students' sexual victimization experiences: Conceptual replication and extension. The Journal of Sex Research, 1-12. https://doi.org/10.1080/00224499.2019.1669135

Anderson, R. E., Cahill, S. P., \& Delahanty, D. L. (2018a). The psychometric properties of the Sexual Experiences SurveyShort Form Victimization (SES-SFV) and characteristics of sexual victimization experiences in college men. Psychology of Men and Masculinity, 19, 25-34. doi:10.1037/men0000073

Anderson, R. E., Cahill, S. P., \& Delahanty, D. L. (2018b). Discordance between the Sexual Experiences Surveys-Short Forms and the Revised Conflict Tactics Scales in college men. Psychology of Violence. doi:10.1037/vio0000199

Anderson, R. E., Goodman, E. L., \& Thimm, S. S. (2020). The Assessment of Forced Penetration: A Necessary and Further Step Toward Understanding Men's Sexual Victimization and Women's Perpetration. Journal of Contemporary Criminal Justice, 104398622093610. https://doi.org/10.1177/1043986220936108

Anderson, R. E., Holmes, S. C., Johnson, N. L., \& Johnson, D. M. (2020) Analysis of a modification to the Sexual Experiences Survey to assess intimate partner sexual violence. Journal of Sex Research. doi

Anderson, R. E., Silver, K. E. S., Ciampaglia, A. M., Vitale, A. M., \& Delahanty, D. L. (2019). The frequency of sexual perpetration in college men: A systematic review of reported prevalence rates from 2000-2017. Trauma, Violence, \& Abuse doi: 10.1177/1524838019860619

Anderson, R. E., Tarasoff, L. A., VanKim, N., \& Flanders, C. (2019). Differences in rape acknowledgment and mental health outcomes across transgender, nonbinary, and cisgender bisexual youth. Journal of Interpersonal Violence, 088626051982976. https://doi.org/10.1177/0886260519829763

Anderson, R. E., Wandrey, R. L., Klossner, S. C., Cahill, S. P., \& Delahanty, D. L. (2017). Sexual minority status \& interpersonal victimization in college men. Psychology of Sexual Orientation and Gender Diversity, 4(1), 130-136. https://doi.org/10.1037/sgd0000204

Buday, S. K., \& Peterson, Z. D. (2015). Men's and women's interpretation and endorsement of items measuring self-reported heterosexual aggression. Journal of Sex Research, 52(9), 1042-1053. https://doi.org/10.1080/00224499.2014.967373

Bureau of Justice Statistics. (2019, September). Criminal Victimization, 2018 (Rep. No. NCJ253043). Retrieved https://www.bjs.gov/content/pub/pdf/cv18.pdf

Canan, S. N., Jozkowski, K. N., Wiersma-Mosley, J. D., Bradley, M., \& Blunt-Vinti, H. (2019). Differences in lesbian, bisexual, and heterosexual eomen's Experiences of sexual assault and rape in a national U.S. sample. Journal of Interpersonal Violence, 088626051986372. https://doi.org/10.1177/0886260519863725

CBS News. (2017, October 17). More than 12M "me TOO" Facebook posts, COMMENTS, reactions in 24 hours. Retrieved April 09, 2020, from https://www.cbsnews.com/news/metoo-more-than-12-million-facebook-posts-commentsreactions-24-hours/

Clement, J. (2019, December 02). Number of Facebook users in the United States from 2017 to 2023. Retrieved April 12, 2020, from https://www.statista.com/statistics/408971/number-of-us-facebook-users/

Cronbach, L. J., \& Meehl, P. E. (1955). Construct validity in psychological tests. Psychological Bulletin, 52, 281-302. Retrieved from http://content.apa.org/journals/bul/52/4/281

Davis, K. C., Gilmore, A. K., Stappenbeck, C. A., Balsan, M. J., George, W. H., \& Norris, J. (2014). How to score the Sexual Experiences Survey? A comparison of nine methods. Psychology of Violence, 4, 445-461. https://doi.org/10.1037/a0037494

Deitz, S. R., Blackwell, K. T., Daley, P. C., \& Bentley, B. J. (1982). Measurement of empathy toward rape victims and rapists. Journal of Personality and Social Psychology, 43, 372-384. https://doi.org/10.1037/0022-3514.43.2.372

Federal Bureau of Investigation [FBI] (2019, September 13). Crime in the United States, 2018 Retrieved from https://ucr.fbi.gov/crime-in-the-u.s/2018/crime-in-the-u.s.-2018/topic-pages/rape

Fisher, B. S. (2009). The effects of survey question wording on rape estimates: Evidence from a quasi-experimental design. Violence Against Women, 15(2), 133147. https://doi.org/10.1177/1077801208329391

Flake, J. K., \& Fried, E. I. (2019, January 17). Measurement schmeasurement: Questionable measurement practices and how to avoid them. https://doi.org/10.31234/osf.io/hs7wm

French, B. H., Tilghman, J. D., \& Malebranche, D. A. (2015). Sexual coercion context and psychosocial correlates among diverse males. Psychology of Men \& Masculinity, 16(1), 42. https://doi.org/10.1037/a0035915 
French, B. H., Suh, H. N., \& Arterberry, B. (2017). Exploratory factor analysis and Psychometric properties of the Sexual Coercion Inventory. The Journal of Sex Research, 54, 962-970. doi:10.1080/00224499.2016.1235129

Hussey, I., \& Hughes, S. (2020). Hidden invalidity among 15 Commonly used measures in Social and Personality Psychology. Advances in Methods and Practices in Psychological Science, 251524591988290. https://doi.org/10.1177/2515245919882903

Johnson, S. M., Murphy, M. J., \& Gidycz, C. A. (2017). Reliability and validity of the Sexual Experiences Survey - Short Forms victimization and perpetration. Violence and Victims, 32, 78-92. doi:10.1891/0886-6708.VV-D-15-00110

Katz, J., \& Tirone, V. (2008). Childhood sexual abuse predicts women's unwanted sexual interactions and sexual satisfaction in adult romantic relationships. Child sexual abuse: Issues and challenges, 67-86.

Koss, M. P. (1993). Rape: Scope, impact, interventions, and public policy responses. American Psychologist, 48(10), 10621069. https://doi.org/10.1037/0003-066X.48.10.1062

Koss, M. P., Abbey, A., Campbell, R., Cook, S., Norris, J., Testa, M., ... White, J. (2007). Revising the SES: A Collaborative process to improve assessment of sexual aggression and victimization. Psychology of Women Quarterly, 31, 357-370. doi:10.1111/j.1471-6402.2007.00385.

Koss, M. P., Gidycz, C. A., \& Wisniewski, N. (1987). The scope of rape: Incidence and prevalence of sexual aggression and victimization in a national sample of higher education students. Journal of Consulting and Clinical Psychology, 55(2), 162-170. http://psycnet.apa.orgjournals/ccp/55/2/162

Littleton, H., Layh, M., Rudolph, K., \& Haney, L. (2018, April 26). Evaluation of the Sexual Experiences Survey-Revised as a screening measure for sexual assault victimization among college students. Psychology of Violence. https://doi.org/10.1037/vio0000191

Martin-Storey, A., Paquette, G., Bergeron, M., Dion, J., Daigneault, I., Hébert, M., \& Ricci, S. (2018). Sexual violence on campus: Differences across gender and sexual minority status. Journal of Adolescent Health. https://doi.org/10.1016/J.JADOHEALTH.2017.12.013

Muehlenhard, C. L., Peterson, Z. D., Humphreys, T. P., \& Jozkowski, K. N. (2017, June 13). Evaluating the one-in-five statistic: Women's risk of sexual assault while in college. Journal of Sex Research. Taylor \& Francis. doi:10.1080/00224499.2017.1295014

Osman, S. L. (2011). Predicting rape empathy based on victim, perpetrator, and participant gender, and history of sexual aggression. Sex Roles, 64, 506-515. https://doi.org/10.1007/s11199-010-9919-7

Osman, S. L. (2016). Predicting rape victim empathy based on rape victimization and acknowledgment labeling. Violence against Women, 22, 767-779. https://doi.org/10.1177/1077801215610864

Parent, M. C. (2013). Handling item-level missing data. The Counseling Psychologist, 41(4), 568-600. https://doi.org/10.1177/0011000012445176

Peterson, Z. D., Voller, E. K., Polusny, M. A., \& Murdoch, M. (2010). Prevalence and consequences of adult sexual assault of men: review of empirical findings and state of the literature. Clinical Psychology Review, 31, 1-24. Doi:10.1016/j.cpr.2010.08.006

Puckett, J. A., Brown, N. C., Dunn, T., Mustanski, B., \& Newcomb, M. E. (2020). Perspectives from Transgender and Gender Diverse People on How to Ask About Gender. LGBT Health, lgbt.2019.0295. https://doi.org/10.1089/lgbt.2019.0295

Smith, C. A., \& Frieze, I. H. (2003). Examining rape empathy from the perspective of the victim and the assailant. Journal of Applied Social Psychology, 33, 476-498. doi:10.1111/j.1559-1816.2003.tb01907.x

Stemple, L., \& Meyer, I. H. (2014). The sexual victimization of men in America: New data challenge old assumptions. American Journal of Public Health, 104, e19-e26.

Strang, E., Peterson, Z. D., Hill, Y. N., \& Heiman, J. R. (2013). Discrepant responding across self-report measures of men's coercive and aggressive sexual strategies. Journal of Sex Research, 50, 458-469. doi:10.1080/00224499.2011.646393

Strang, E., \& Peterson, Z. D. (2017). Unintentional Misreporting on Self-Report Measures of Sexually Aggressive Behavior: An Interview Study. Journal of Sex Research, 54, 971-983. doi.org/10.1080/00224499.2017.1304519

Struckman-Johnson, C., Struckman-Johnson, D., \& Anderson, P. B. (2003). Tactics of sexual coercion: When men and women won't take no for an answer. Journal of Sex Research, 40, 76-86. doi.org/10.1080/00224490309552168

Tabachnick, B. G., \& Fidell, L. S. (2007). Using multivariate statistics (5th ed.). Boston, MA, USA: Allyn \&Bacon/Pearson Education. doi.org/10.1037/022267

Turchik, J. A., \& Hassija, C. M. (2014). Female sexual victimization among college students: Assault severity, health risk behaviors, and sexual functioning. Journal of Interpersonal Violence, 29, 2439-2457. doi.org/10.1177/0886260513520230

Wade, J. C., \& Donis, E. (2007). Masculinity ideology, male identity, and romantic relationship quality among heterosexual and gay men. Sex Roles, 57(9-10), 775-786. 
Weir, J. A., \& Wrightsman, L. S. (1990). The determinants of mock jurors' verdicts in a rape case. Journal of Applied Social Psychology, 20(11, Pt 2), 901-919.

Wolitzky-Taylor, K. B., Resnick, H. S., McCauley, J. L., Amstadter, A. B., Kilpatrick, D. G., \& Ruggiero, K. J. (2011). Is Reporting of Rape on the Rise? A Comparison of Women With Reported Versus Unreported Rape Experiences in the National Women's Study-Replication. Journal of Interpersonal Violence, 26(4), 807-832. https://doi.org/10.1177/0886260510365869

Woods, C. M. (2006). Careless Responding to Reverse-Worded Items: Implications for Confirmatory Factor Analysis. Journal of Psychopathology and Behavioral Assessment, 28(3), 186. https://doi.org/10.1007/s10862-005-9004-7

\section{Author Biographies}

RaeAnn E. Anderson (PhD, University of Wisconsin-Milwaukee, 2015) is currently an Assistant Professor in Clinical Psychology at the University of North Dakota. She completed her postdoctoral training at Kent State University and her bachelor's at the University of Kansas. Her research interests are understanding basic behavioral processes in sexual victimization and sexual perpetration in order to inform sexual assault risk reduction and prevention programs, respectively.

Emily M. Carstens Namie (Ph.D., University of North Dakota, 2019) is currently a Postdoctoral Research Fellow in the Sexual Violence Prevention Lab at the University of North Dakota where she is researching behavioral processes in sexual perpetration. Her doctoral training is in social cognition as applied to psychology and law. Her additional research interests include the influence of the internet and social media on juror decision-making; eye witness identification and errors; and eye witness memory, errors and false memory.

Erica L. Goodman (M.A., University of North Dakota, 2017) has a master's degree in clinical psychology and is currently on doctoral internship at Northwestern University. Her thesis used structural equation modeling to assess comorbid indicators of non-suicidal self-injury and eating disorder psychopathology. Her dissertation is investigating facets of loss-of-control eating in a non-clinical sample. Erica continues to do clinical work and research surrounding issues related to eating pathology and, recently, sexual violence perpetration and victimization. 
Table I

Frequences by Type of Victimization on each Questionnaire

\begin{tabular}{|c|c|c|c|c|c|}
\hline & $\begin{array}{c}\text { Hetero } \\
\text { women, } \\
n=322 \\
\%\end{array}$ & $\begin{array}{l}\text { SM } \\
\text { women, } \\
n=45 \\
\%\end{array}$ & $\begin{array}{l}\text { Hetero } \\
\text { men, } \\
n=253 \\
\%\end{array}$ & $\begin{array}{l}\text { SM men, } n \\
=45 \\
\%\end{array}$ & $\begin{array}{l}\text { Gender } \\
\text { minorities, } \\
n=8 \\
\%\end{array}$ \\
\hline Unwanted contact - SES & 33.9 & 37.8 & 9.1 & 22.2 & 75.0 \\
\hline Enticement - PRSPS & 47.8 & 44.4 & 26.5 & 33.3 & 50.0 \\
\hline Verbal coercion - SES & 35.6 & 44.4 & 12.6 & 24.4 & 50.0 \\
\hline Verbal coercion - PRSPS & 52.5 & 51.1 & 27.3 & 42.2 & 87.5 \\
\hline Substance use - SES & 27.6 & 33.3 & 9.5 & 17.8 & 25.0 \\
\hline Substance use - PRSPS & 23.3 & 17.8 & 10.7 & 20.0 & 12.5 \\
\hline Physical force - SES & 20.5 & 17.8 & 5.1 & II.I & 37.5 \\
\hline Physical force - PRSPS & 18.3 & 31.1 & 7.5 & 17.8 & 25.0 \\
\hline Misuse authority - PRSPS & 6.5 & II.I & 3.2 & 9.1 & 12.5 \\
\hline Rape - SES & 30.4 & 31.1 & 8.7 & 25.0 & 50.0 \\
\hline
\end{tabular}

Note. Hetero $=$ heterosexual, $S M=$ sexual minority, substance use $=$ substance use facilitated, $S E S=$ Sexual Experience Survey - Short Form Victimization, PRSPS $=$ Post-Refusal Sexual Persistence Scale - Victimiation 
Table 2

Correlations between the Victimization Questionnaires by Group

\begin{tabular}{llll}
\hline & $\begin{array}{l}\text { SES-SFV \& } \\
\text { PRSPS-V, Di- } \\
\text { chotomous } \\
\text { scores }\end{array}$ & $\begin{array}{l}\text { SES-SFV \& } \\
\text { PRSPS-V, } \\
\text { Continuous } \\
\text { scores }\end{array}$ & $\begin{array}{l}\text { z test for difference } \\
\text { between paired }\end{array}$ \\
correlations
\end{tabular}

Note. SES-SFV = Sexual Experiences Survey - Short Form Victimization, PRSPS-V = Post-Refusal Persistence Scale - Victimization. Letter subscripts indicate the pairs of correlations that were compared. *all correlations between the SES-SFV and PRSPS-V were significant, $p<.001$

Table 3

Spearman's Correlations between the REM-V, SES-SFV and PRSPS-V by Group

\begin{tabular}{lllll}
\hline & $\begin{array}{l}\text { REM-V \& } \\
\text { SES-SFV } \\
\text { (continu- } \\
\text { ous) }\end{array}$ & $\begin{array}{l}\text { REM-V \& } \\
\text { PRSPS-V } \\
\text { (continu- } \\
\text { ous) }\end{array}$ & $\begin{array}{l}\text { Power }{ }^{\circ} \text { z test for difference } \\
\text { smallest } \\
\text { effect }\end{array}$ & $\begin{array}{l}\text { in strength of rela- } \\
\text { tionships }\end{array}$ \\
\hline Total sample, $N=673$ & $.27^{*}$ & $.30^{*}$ & 1.00 & $z=.60, p=.550$ \\
Sexual minority women, $n=45$ & .23 & .19 & .35 & $z=.19, p=.847$ \\
Heterosexual women, $n=322$ & $.25^{*}$ & $.29 *$ & 1.00 & $z=.54, p=.596$ \\
Sexual minority men, $n=45$ & .21 & .24 & .40 & $z=.14, p=.884$ \\
Heterosexual men, $n=253$ & $.12(p=.07)$ & $.19 *$ & .60 & $z=.80, p=.422$ \\
Sexual minority participants, $n=97 \pm$ & $.21 *$ & $.23^{*}$ & .67 & $z=.14, p=.885$ \\
\hline
\end{tabular}

Note. REM-V = Rape Empathy for Victims, SES-SFV = Sexual Experiences Survey - Short Form Victimization, PRSPS- $V=$ Post-Refusal Persistence Scale - Victimization;. \pm This $n$ is larger because it includes gender minority participants who identified as sexual minorities. ${ }^{\circ}$ one-tailed 
Figure I

Differences in rape empathy by gender and sexual identity

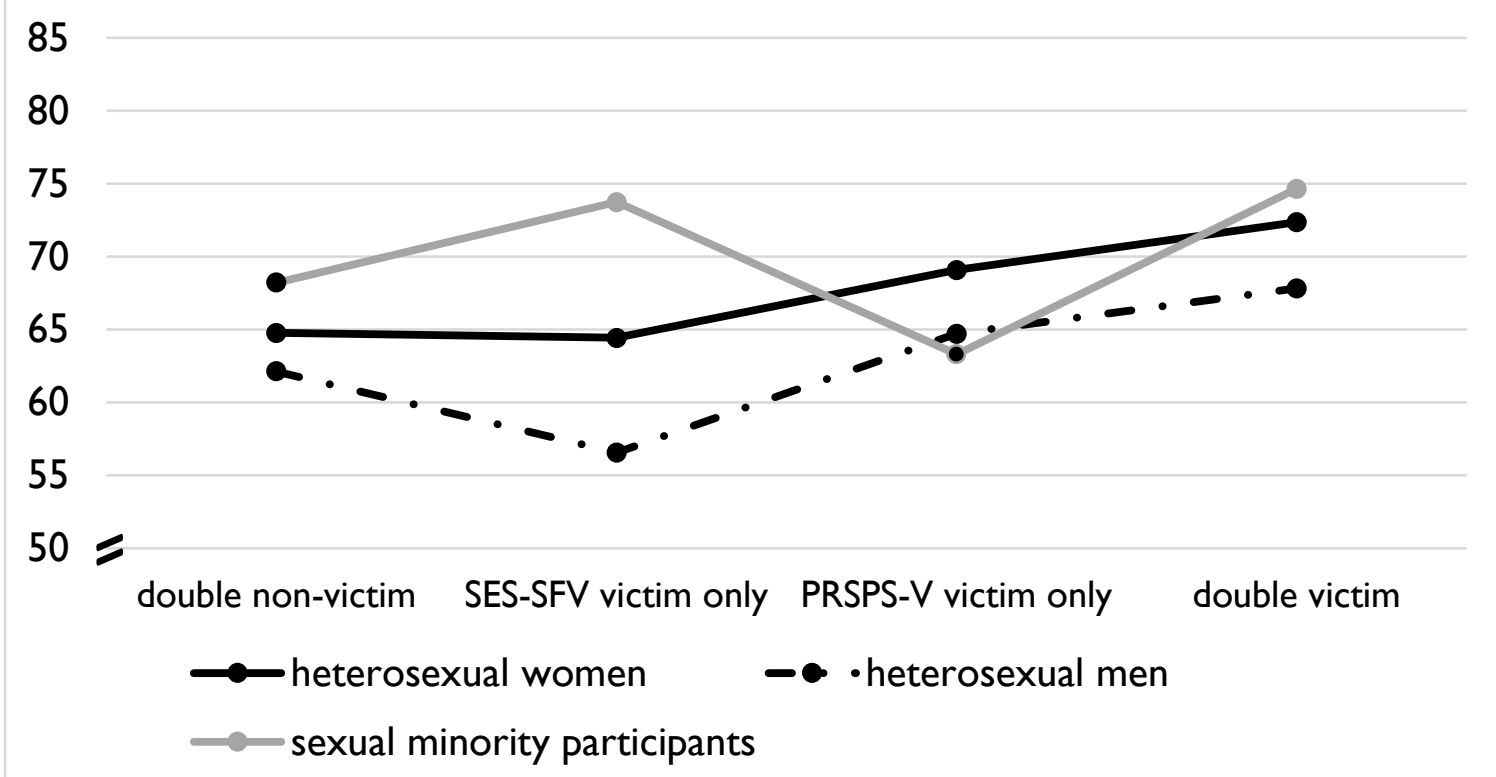

Note. The possible range of scores is 23-105, the range was truncated for ease of interpretation. SES-SFV = Sexual Experiences Survey-Short Form Victimization, PRSPS-V = Post-Refusal Sexual Persistence Scale-Victimization

Table 4

Means and standard deviations for one way ANOVA of rape empathy for victims by group (accompaniment for Figure I)

\begin{tabular}{llllllll}
\hline Group & $\begin{array}{l}\text { Double } \\
\text { non-victims }\end{array}$ & $\begin{array}{l}\text { SES-SFV } \\
\text { victims } \\
\text { only }\end{array}$ & $\begin{array}{l}\text { PRSPS-V } \\
\text { victims } \\
\text { only }\end{array}$ & $\begin{array}{l}\text { Double vic- } \\
\text { tims }\end{array}$ & $\begin{array}{l}\text { F(dfI, } \\
\text { df2) }\end{array}$ & $\begin{array}{l}\text { partial } \\
\eta^{2}\end{array}$ & $p$ \\
\cline { 2 - 6 } & $M, S D, n$ & $M, S D, n$ & $M, S D, n$ & $M, S D, n$ & & & \\
\hline Heterosexual women, & $* 64.76$, & \pm 64.44, & 69.08, & $* \pm 72.36$, & 8.14 & .072 & $<.0001$ \\
$n=322$ & $14.28, I 12$ & $18.28, I 7$ & $9.67,44$ & $11.66,146$ & $(3,315)$ & & \\
Heterosexual men, $n$ & $* 62.13$, & \pm 56.56, & 64.73, & $* \pm 67.82$, & 3.28 & .038 & .022 \\
$=253$ & $12.19,158$ & $12.99,9$ & $13.11,45$ & $13.30,41$ & $(3,249)$ & & \\
Sexual minority par- & 68.21, & 73.75, & 63.30, & 74.35, & 2.65 & .079 & .053 \\
ticipants, $n=97 \pm$ & $13.52,41$ & $13.96,4$ & $21.00,10$ & $10.45,42$ & $(3,93)$ & & \\
\hline
\end{tabular}

Note. $\pm p=.07-.08,{ }^{*} p<.05$ 